\title{
Effects of particle shape and temperature on compaction of copper powder at micro scale
}

\author{
Chao-Cheng Chang* and Ming-Ru Wu \\ Department of Mold and Die Engineering, National Kaohsiung University of Applied Sciences, Kaohsiung, 80778, Taiwan
}

\begin{abstract}
This study investigated the effects of particle shape and temperature on the compaction of copper powder at micro scale. Copper powder particles were compressed inside a cylindrical die cavity with $2 \mathrm{~mm}$ diameter to form compacts with about $3 \mathrm{~mm}$ height. Two kinds of particle shapes, spherical and dendritic, and two forming temperatures, room temperature and $400^{\circ} \mathrm{C}$, were considered in the experiments. Some of the produced compacts were further sintered at $600^{\circ} \mathrm{C}$. The study also used simple upsetting tests to investigate the characteristics of the deformation of the compacts under compressive stresses. The results showed that the compacts produced at room temperature demonstrated brittle deformations. However, by increasing the forming temperature to $400^{\circ} \mathrm{C}$, ductile deformations have been observed on the compacts of dendritic particles. Furthermore, the sintering treatment resulted in increases in dimensions, decreases in relative density and hardness, and an increase in ductility. It also led to pore growths which have been seen on scanning-electron microscope images. These phenomena were most significant in the dendritic powder compacts which were produced at $400^{\circ} \mathrm{C}$ and treated by the sintering process.
\end{abstract}

\section{Introduction}

Micro forming processes have been developed in recent years with the objective of fabricating micro metal parts available for the mass production in the fields of electronics products, life science, and transport industry. To rapidly fulfil the need in markets and reduce the lead time of the micro metal parts, the powder metallurgy (PM) process which can produce parts at net or near-net shape is widely interested in academia and industry.

The PM process basically consists of powder production, blending, compaction, sintering, and finishing operations. By using different methods of compressing and shaping, PM has been developed into several processes including cold isostatic pressing (CIP), hot isostatic pressing (HIP), and powder injection molding (PIM). PM has not only been used in industrial products but also in medical applications, such as porous metals for use in orthopaedic applications [1]. On the other hand, the direct laser sintering process of metallic powder, which does not require a compaction of powder, has also developed for rapid tooling [2] and producing metallic microstructures [3]. Moreover, it is possible to use a direct powder rolling process for manufacturing titanium strips [4].

Similar to PIM, micro powder injection molding, which can produce the micro-components of metal, ceramic and hard materials, is also an attractive process for the mass production of complex micro-components with features at the micrometer or sub-micrometer scale $[5,6]$. The size and shape of powder particle, which may be described in terms of aspect ratio or shape factor, greatly influence the operations of PM and the quality of the product [7]. The shape factor, which is the ratio of surface area of the particle to its volume, affects the contact between particles that has an important effect on their behavior in processing them. For the same pressure of compaction, the coarse powder particles result in a higher density of the compact than the fine powder particles [8]. In addition to the effects of shape and size, temperature affects the process of PM, especially playing an important role on the bonding of the particles. It is possible to vary compaction temperature for producing a PM product with a graded microstructure which has a nearly homogeneous solid at the high-temperature side and clearly porous structure at the low-temperature side [9]. Furthermore, an increase in the sintering temperature may result in faster densification and sintering as demonstrated in the PIM process of tungsten carbide components in which the relative density and hardness increase dramatically at a certain sintering temperature [10]. Recently, Bai et.al [11] proposed a direct forging process of powdered nickel-based superalloys. In the proposed process, encapsulated and vacuumed powder particles were heated up to a forming temperature and forged directly at high speed to the final shape. The process provides an attractive approach for producing near net-shape fine grained products at low cost and with high productivity.

In this study, copper powders were compressed inside a cylindrical die cavity to form compacts with 2 $\mathrm{mm}$ diameter. Two kinds of particle shapes in copper powders, dendritic and spherical shapes, were considered. To investigate the effect of temperature, experiments

Corresponding author: ccchang@kuas.edu.tw 
were conducted on two forming conditions which were at room temperature and in vacuum at an elevated temperature. Some of the produced compacts were further treated by sintering. Furthermore, the study used simple upsetting tests to investigate the characteristics of the deformation of the compacts under compressive stresses. The dimension, relative density, hardness, and microstructure of the produced compacts were investigated.

\section{Experimental procedures}

In this study, copper powder particles were compressed inside the die cavity with $2 \mathrm{~mm}$ diameter to form micro cylindrical compacts as illustrated by Fig. 1. Two shapes of copper particles, spherical and dendritic shapes, and two forming temperatures, room temperature and $400^{\circ} \mathrm{C}$, were considered in experiments. Some of the produced compacts were further treated by sintering. Therefore, there were 8 process conditions according to various particle shapes and temperature, and considering with or without sintering to produce compacts. The compacts were subsequently compressed by the flat dies in simple upsetting tests (Fig. 2) for obtaining the stress-strain curves which can provide information about the deformation of the compacts under compressive stresses. The study also examined the properties of the compacts including dimension, relative density, hardness, and microstructure. Fig. 3 displays the flowchart of the study.

To prevent the oxidation of copper powder in the compacting process at an elevated temperature, a vacuum chamber for experiments was developed. Fig. 4 shows the schematic diagram of the experimental setup in which the powder particles were heated by the die placed inside the vacuum chamber. The material of the vacuum chamber was stainless steel and the die components (Fig. 5) were mainly made of tool steel (JIS SKD 61). The developed vacuum chamber was installed on an electro press with a capacity of $50 \mathrm{kN}$ and a positioning accuracy of $10 \mu \mathrm{m}$, as shown in Fig. 6 .

The study used spherical powder particles with sizes ranging from 14 to $25 \mu \mathrm{m}$ and dendritic powder particles with a mean size of $45 \mu \mathrm{m}$ in experiments to investigate the effect of particle shape. Fig. 7 shows scanningelectron microscope (SEM) images of the copper powder particles. By carefully controlling the weight of the powder and feeding them into the die cavity, the powder compacts with $80 \pm 1 \mathrm{mg}$ and $2 \mathrm{~mm}$ diameter were produced by a punch speed of $0.1 \mathrm{~mm} / \mathrm{s}$ and a maximum load of $5.88 \mathrm{kN}(1872 \mathrm{MPa})$. In the experiments conducted at $400^{\circ} \mathrm{C}$, the powder particles were directly fed into the die cavity and heated with a rate of $40^{\circ} \mathrm{C}$ per minute inside the vacuum chamber with a condition of $2.6 \times 10^{-2}$ Torr before the compaction process was carried out. The height of the produced powder compact was about $3 \mathrm{~mm}$ and varied with the shape of particle and forming temperature. Furthermore, some of the powder compacts produced at room temperature and $400^{\circ} \mathrm{C}$ were subsequently treated by sintering in vacuum at $600^{\circ} \mathrm{C}$ for 1 hour and cooled down to room temperature inside the furnace. The powder compacts obtained from different processing conditions were compressed by two flat dies at a die speed of $0.1 \mathrm{~mm} / \mathrm{s}$ to perform simple upsetting tests. To reduce the friction at the contact interfaces between the powder compact and dies in the tests, molybdenum disulfide $\left(\mathrm{MoS}_{2}\right)$ based lubricants were applied. Fig. 8 presents some of dendritic copper powder compacts and the deformed compacts from simple upsetting tests.

The micrographs of the fabricated powder compacts were taken using an SEM to reveal the microstructures. By measuring the dimensions of the powder compact and its weight, the volume was calculated and thus relative density can be estimated. Furthermore, hardness numbers across the section of the powder compact were determined using micro Vickers hardness.

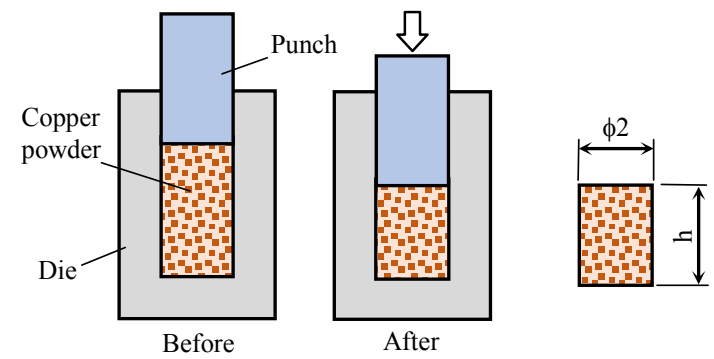

Fig. 1. Schematic illustration of powder compaction and dimensions of powder compact.
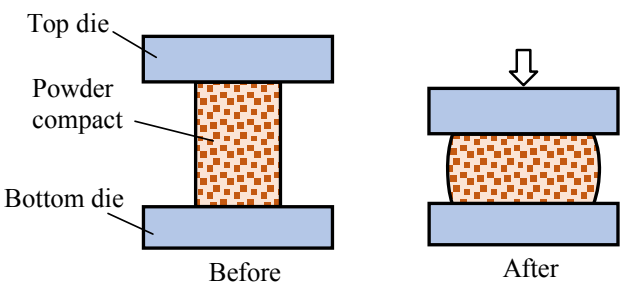

Fig. 2. Schematic illustration of simple upsetting test.

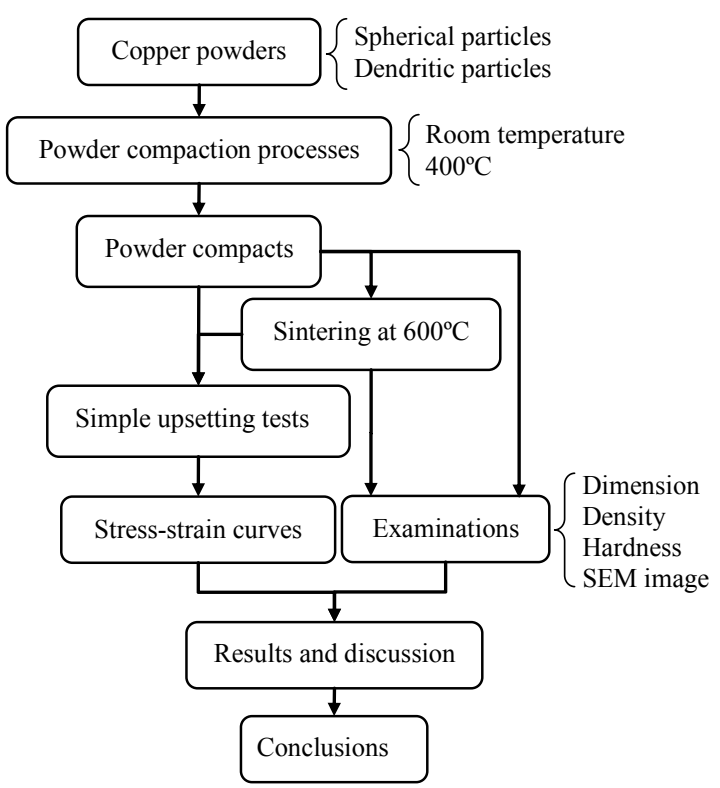

Fig. 3. Flowchart of the study. 


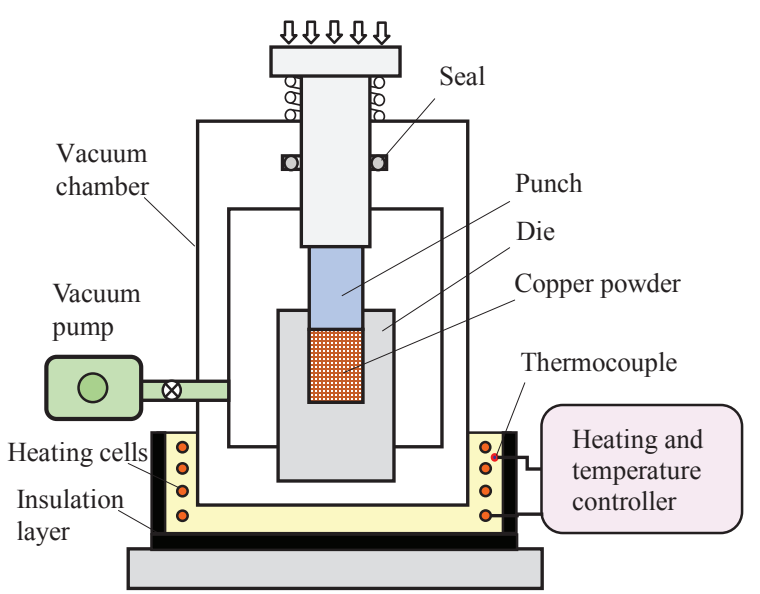

Fig. 4. Schematic diagram of the experimental setup.

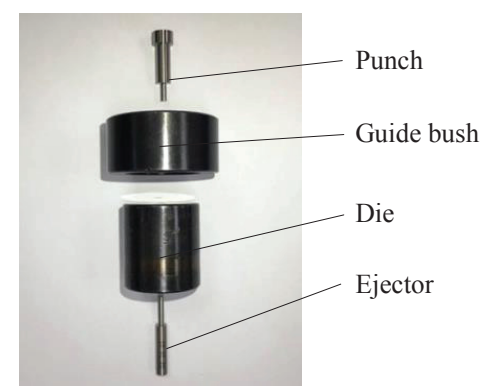

Fig. 5. The die components for experiments.

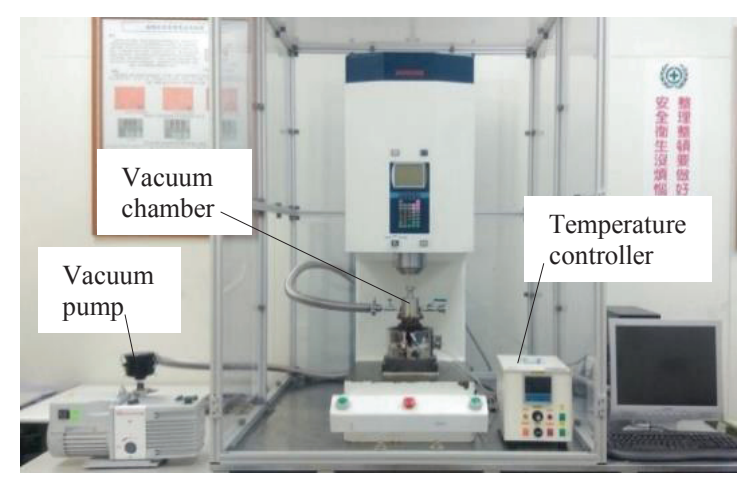

Fig. 6. The electro press installed with the vacuum chamber.

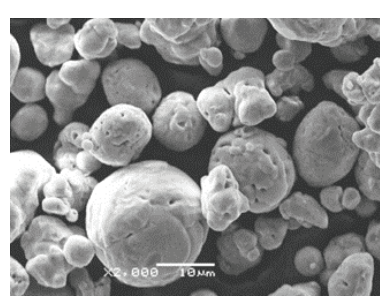

(a) Spherical powder

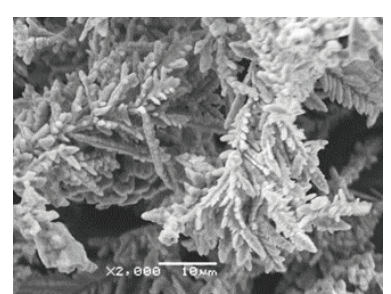

(b) Dendritic powder
Fig. 7. SEM images of copper powder particles.

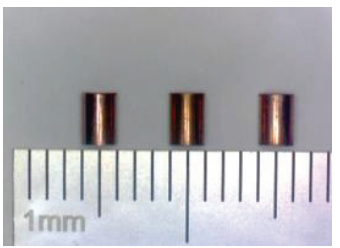

(a) Powder compacts

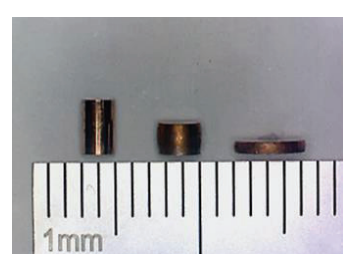

(b) Deformed powder compacts

Fig. 8. The powder compacts and deformed powder compacts from simple upsetting tests.

\section{Results and discussion}

\subsection{Dimensions and relative densities}

The diameters and heights of the produced powder compacts (Fig. 9) were measured to understand the variations in dimensions and used to calculate the volumes for estimating the densities. Tables 1 and 2 list the dimensions of spherical and dendritic powder compacts, respectively. These data were average values of the measurements from 12 powder compacts. For the same weight and compressive pressure, the compacts of dendritic particles had smaller heights than those of spherical particles on the condition without sintering. The phenomena occurred in the compaction processes at room temperature as well as $400^{\circ} \mathrm{C}$. The results implied that dendritic particles led to a higher relative density. Furthermore, after the spherical powder compacts produced at room temperature were sintered, their average diameter and height slightly increased by $0.5 \%$ and $0.6 \%$, respectively, as summarised in Table 3 . Raising the forming temperature to $400^{\circ} \mathrm{C}$, the increase in the dimensions became greater. The sintering treatment had more considerable effects on the expansion of the dendritic powder compacts than those of the spherical powder compacts. The increase of the diameter and height raised by $5.2 \%$ and $10.4 \%$ respectively, in the powder compact produced at $400^{\circ} \mathrm{C}$ and treated by sintering.

In this study, the relative density was the ratio of the density of the copper powder compact to the density of solid copper. By using the measured weights and dimensions of the compacts, their densities and relative densities were calculated. Fig. 10 shows that the relative densities were about $93 \%$ in the compacts of spherical particles produced at both room temperature and $400^{\circ} \mathrm{C}$. The effect of forming temperature on the relative density was not significant. The phenomena also occurred in the compacts of dendritic particles but the relative densities were higher and increased to about $97 \%$. After the compacts were treated by the sintering process, the relative densities decreased. In the cases of room temperature, the relative densities of sintered compacts of spherical and dendritic particles were about $92 \%$ and $87 \%$, respectively. The relative densities dramatically decreased in the cases of $400^{\circ} \mathrm{C}$. In particularly, the sintered compact of dendritic particles had the lowest relative density about $78 \%$. 


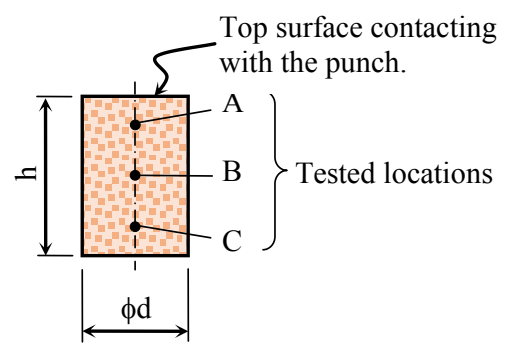

Fig. 9. Illustration of the dimensions and locations on the section of the powder compact for hardness tests and SEM images.

Table 1. Dimensions of spherical powder compacts.

\begin{tabular}{|c|c|c|c|c|}
\hline $\begin{array}{c}\text { Particle } \\
\text { shape }\end{array}$ & \multicolumn{4}{|c|}{ Spherical } \\
\hline $\begin{array}{c}\text { Compaction } \\
\text { temperature }\end{array}$ & \multicolumn{2}{|c|}{ Room temperature } & \multicolumn{2}{|c|}{$400^{\circ} \mathrm{C}$} \\
\hline Treatment & $\begin{array}{c}\text { Without } \\
\text { sintering }\end{array}$ & Sintered & $\begin{array}{c}\text { Without } \\
\text { sintering }\end{array}$ & Sintered \\
\hline $\mathrm{d}(\mathrm{mm})$ & 2.001 & 2.019 & 2.003 & 2.072 \\
\hline $\mathrm{h}(\mathrm{mm})$ & 3.002 & 3.031 & 2.989 & 3.091 \\
\hline
\end{tabular}

Table 2. Dimensions of dendritic powder compacts.

\begin{tabular}{|c|c|c|c|c|}
\hline $\begin{array}{c}\text { Particle } \\
\text { shape }\end{array}$ & \multicolumn{4}{|c|}{ Dendritic } \\
\hline $\begin{array}{c}\text { Compaction } \\
\text { temperature }\end{array}$ & \multicolumn{2}{|c|}{ Room temperature } & \multicolumn{2}{|c|}{$400^{\circ} \mathrm{C}$} \\
\hline Treatment & $\begin{array}{c}\text { Without } \\
\text { sintering }\end{array}$ & Sintered & $\begin{array}{c}\text { Without } \\
\text { sintering }\end{array}$ & Sintered \\
\hline $\mathrm{d}(\mathrm{mm})$ & 2.009 & 2.052 & 2.002 & 2.103 \\
\hline $\mathrm{h}(\mathrm{mm})$ & 2.940 & 3.192 & 2.934 & 3.207 \\
\hline
\end{tabular}

Table 3. Increase of dimensions after sintering.

\begin{tabular}{|c|c|c|c|c|}
\hline $\begin{array}{c}\text { Particle } \\
\text { shape }\end{array}$ & \multicolumn{2}{|c|}{ Spherical } & \multicolumn{2}{c|}{ Dendritic } \\
\hline $\begin{array}{c}\text { Compaction } \\
\text { temperature }\end{array}$ & $\begin{array}{c}\text { Room } \\
\text { temp. }\end{array}$ & $400^{\circ} \mathrm{C}$ & $\begin{array}{c}\text { Room } \\
\text { temp. }\end{array}$ & $400^{\circ} \mathrm{C}$ \\
\hline $\begin{array}{c}\text { Increase of } \\
\mathrm{d}(\%)\end{array}$ & 0.5 & 3.4 & 2.2 & 5.2 \\
\hline $\begin{array}{c}\text { Increase of } \\
\mathrm{h}(\%)\end{array}$ & 0.6 & 3.5 & 8.2 & 10.4 \\
\hline
\end{tabular}

Spherical, RT

Spherical, RT, Sintered

Spherical, $400^{\circ} \mathrm{C}$

Spherical, $400^{\circ} \mathrm{C}$, Sintered

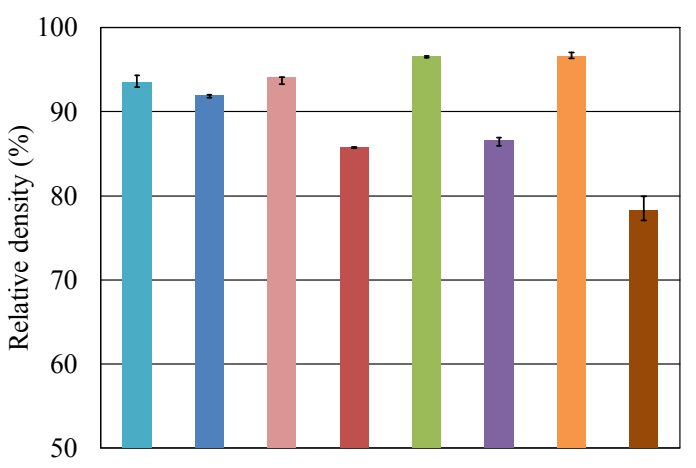

Fig. 10. Relative densities.

\subsection{Hardness}

Hardness tests were performed at three locations on the section of the powder compact as illustrated by Fig. 9 . To correctly observe the hardness variations in the powder compacts, the surfaces contacting with the punch were marked after the compaction processes. Fig. 11 demonstrates that the dendritic particles resulted in greater hardness numbers ranging from about 130 (at location C) to $142 \mathrm{HV}$ (at location A) in the cases of room temperature, and about 141 to $152 \mathrm{HV}$ in the cases of $400^{\circ} \mathrm{C}$. For the compacts made of spherical particles, the hardness numbers varied from about 106 to $123 \mathrm{HV}$. However, the effect of particle shape on the hardness was different in the sintered compacts. The hardness numbers dropped from high values to a range from about 63 to $87 \mathrm{HV}$ in the cases of spherical particles. The effect of the sintering process was more significant in the cases of dendritic particles in which the hardness number decreased to $64 \mathrm{HV}$ at location A for the process at room temperature, and to $46 \mathrm{HV}$ at location $\mathrm{C}$ for the process at $400^{\circ} \mathrm{C}$. Moreover, the highest and lowest numbers appeared at locations $\mathrm{A}$ and $\mathrm{C}$, respectively, for all process conditions. The hardness number slightly decreased from the upper to lower locations that probably indicated the density variation in the powder compacts.

\subsection{Micrographs}

The SEM images of the spherical powder compacts produced at room temperature (Fig. 12) clearly revealed the deformations and boundaries of the particles in the case without the sintering treatment. However, in the sintered compacts, most of the boundaries have disappeared and pores have developed that could be caused by the bonding of the particles in the sintering process. The location A had less quantity of pores than the location $\mathrm{C}$. This indicated that the quantity of pores slightly increases with the locations away from the top surface which contacted with the punch in the 
compaction process. In the cases produced at $400^{\circ} \mathrm{C}$ as presented in Fig. 13, the deformations and boundaries of particles were also visible. Furthermore, the effects of sintering on the bonding of particles and the development of pores were similar to those in the cases of room temperature. Comparing Figs. 12 and 13 shows that an increase in the compaction temperature to $400^{\circ} \mathrm{C}$ could improve the bonding of the particles that leads to the vanish of the boundaries of the particles.

Spherical, RT

Spherical, RT, Sintered

Spherical, $400^{\circ} \mathrm{C}$

Spherical, $400^{\circ} \mathrm{C}$, Sintered

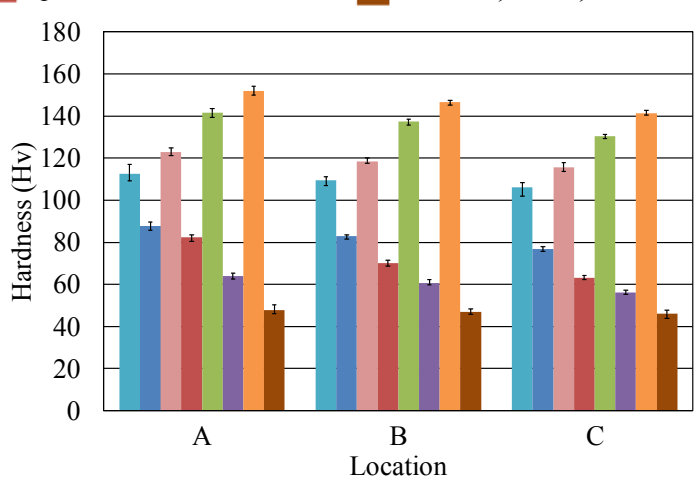

Fig. 11. Hardness

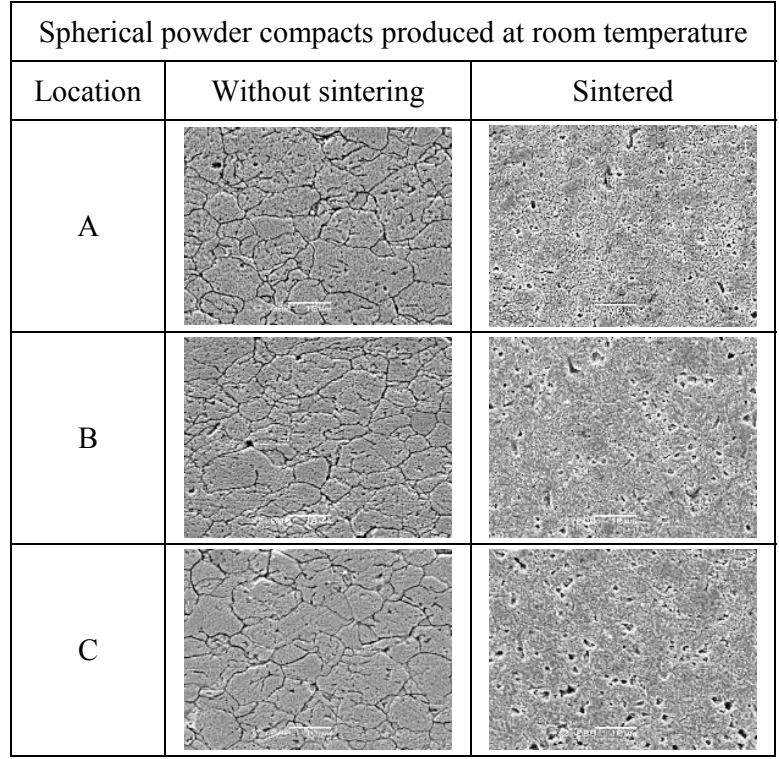

Fig. 12. SEM images of spherical powder compacts produced at room temperature.

The micrographs of the dendritic powder compacts obtained at room temperature displayed smaller boundaries of particles as presented in Fig. 14. After the sintering process, the bonding of the particles has occurred. Moreover, comparing Figs. 12 and 14 shows that the sizes of the pores in the dendritic powder compacts are smaller than those in the spherical powder compacts. This difference could be caused by an easy fracture and deformation of dendritic particles that leads to smaller sizes of particles in the compaction process. Furthermore, Fig. 15 displays that the bonding of particles has also occurred in the powder compacts produced at $400^{\circ} \mathrm{C}$ on the conditions without as well as with sintering. Some pores can also be clearly found and appear greater sizes in the cases with the sintering process. These trends could lead to lower densities and are in line with the previously discussed variations of the relative densities.

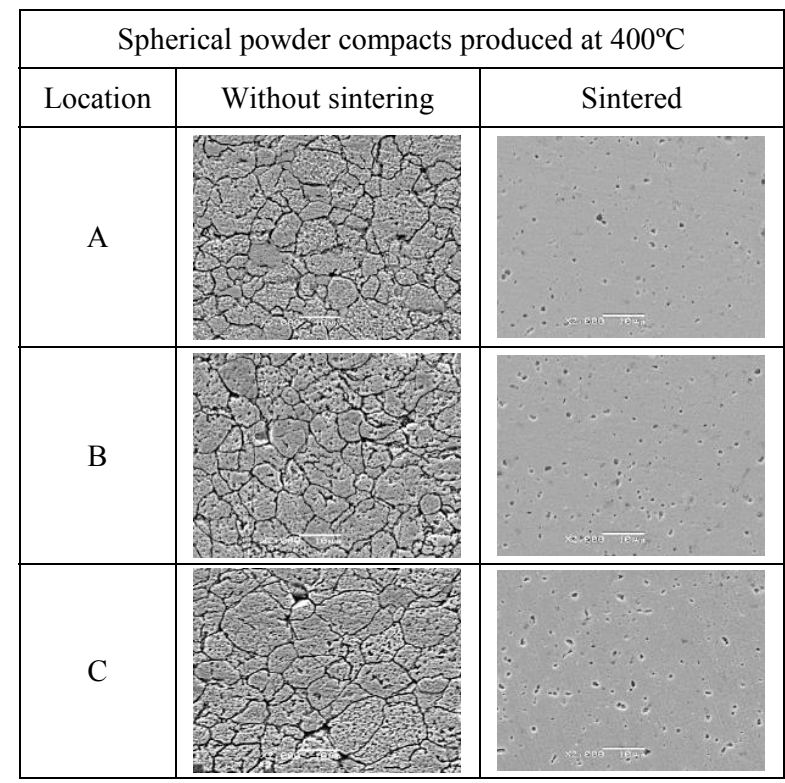

Fig. 13. SEM images of spherical powder compacts produced at $400^{\circ} \mathrm{C}$.

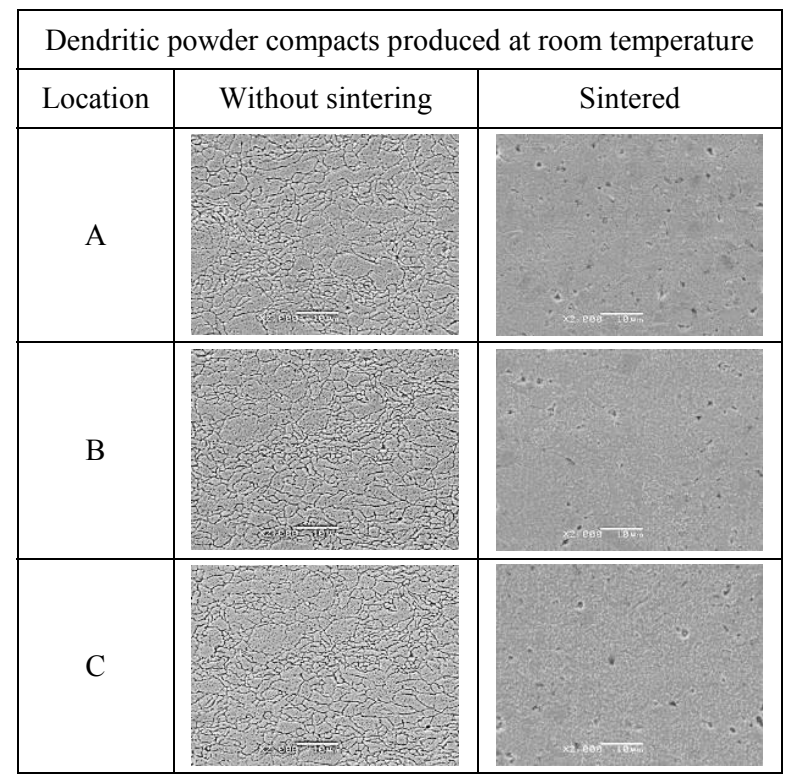

Fig. 14. SEM images of dendritic powder compacts produced at room temperature. 


\begin{tabular}{|c|c|c|}
\hline \multicolumn{3}{|c|}{ Dendritic powder compacts produced at $400^{\circ} \mathrm{C}$} \\
\hline Location & Without sintering & Sintered \\
\hline A & & \\
\hline B & & \\
\hline $\mathrm{C}$ & & \\
\hline & & \\
\hline
\end{tabular}

Fig. 15. SEM images of dendritic powder compacts produced at $400^{\circ} \mathrm{C}$.

\subsection{Stress-strain curves}

The true stress-true strain curves of powder compacts are presented in Fig. 16. The copper powder compacts produced at room temperature from both spherical and dendritic particles demonstrated elastic deformations to a maximum compressive stress about $400 \mathrm{MPa}$ and sudden fractures. The phenomena were also observed in the compacts of the spherical particles produced at $400^{\circ} \mathrm{C}$ although a slightly greater strength of $450 \mathrm{MPa}$ was found. These results were probably caused by weak bonding of the particles that commonly appears in a green compact from a PM process. However, in the cases of dendritic particles, an increase of the compaction temperature to $400^{\circ} \mathrm{C}$ improved the ductility of the powder compact. Its true stress-true strain curve showed little strain-hardening and had a stress about 450 $\mathrm{MPa}$ at a strain of 0.8 .

The sintering process significantly influenced the true stress-true strain curves of the powder compacts, and causes an increase in the ductility and great strainhardening effects, as displayed in Fig. 16. The strength was higher in the cases of spherical particles than those of dendritic particles. It can also be seen that the dendritic powder compact formed at $400^{\circ} \mathrm{C}$ and treated by the sintering process resulted in the lowest strength among all tests. Moreover, the true stress-true strain curves of the sintered dendritic copper powder compacts were close to the curve of an annealed solid copper.

\section{Conclusions}

The study investigated the effects of particle shape and temperature on the compaction of copper powder at micro scale. Copper powder particles were compressed inside a cylindrical die cavity to form powder compacts. Two kinds of particle shapes and two forming temperatures were considered in the experiments. Some of the produced compacts were further treated by the sintering process. The study also used simple upsetting tests to investigate the characteristics of deformation of the powder compacts under compressive stresses. The results showed that the powder compacts produced at room temperature demonstrated brittle deformations. However, by increasing the forming temperature to $400^{\circ} \mathrm{C}$, ductile deformations have been observed on the compacts of dendritic particles. Furthermore, the sintering treatment resulted in increases in dimensions, decreases in relative density and hardness, an increase in ductility, and pore growths. The phenomena were most significant in the dendritic powder compacts produced at $400^{\circ} \mathrm{C}$ and treated by the sintering process.

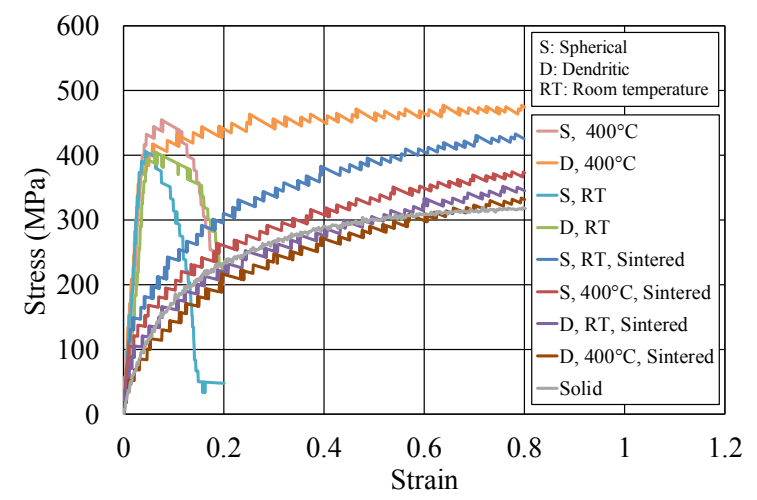

Fig. 16. True stress-true strain curves.

The authors gratefully acknowledge the financial support from the Ministry of Science and Technology, Taiwan (Grant No. MOST 105-2221-E-151-018).

\section{References}

1. G. Ryan, A. Pandit, D. P. Apatsidis. Biomaterials 27(13), 2651 (2006)

2. A. Simchi, F. Petzoldt, H. Pohl, J. Mater. Process. Technol., 141(3), 319 (2003)

3. Y. Kathuria, Surf. Coat. Tech., 116643 (1999)

4. S. Chikosha, T. Shabalala, H. Chikwanda, Powder Technology, 264, 310 (2014)

5. R. Zauner, Microelectron. Eng., 83(4) 1442 (2006)

6. S. Heng, M. R. Raza, N. Muhamad, A. B. Sulong, A. Fayyaz, Int. J. Refract Metals Hard Mater., 45, 189 (2014)

7. K. Nishiyabu. Micro metal powder injection molding In Wang, J., ed. Some critical issues for injection molding (InTech, 2012).

8. S. Kalpakjian, S. R. Schmid, Manufacturing engineering and technology (SI 7e Ed., Pearson Singapore, 2013)

9. B. Kieback, A. Neubrand, H. Riedel, Mat. Sci. Eng. A-Struct., 362(1), 81 (2003)

10. A. Fayyaz, N. Muhamad, A. B. Sulong, J. Rajabi, Y. N. Wong, J. Mater. Process. Technol., 214(7), 1436 (2014)

11. Q. Bai, J. Lin, J. Jiang, T. Dean, J. Zou, G. Tian, Mat. Sci. Eng. A-Struct, 621, 68 (2015) 